\title{
Analysis on Research and Education for Electromagnetic-Applied Subjects with Finite Difference Time Domain Theory
}

\author{
Hla Myo Tun ${ }^{1}$, Thida Than ${ }^{1}$, Myint Myint $\operatorname{Than}^{1}$, Khin Sandar Tun ${ }^{1}$, Zaw Min Naing ${ }^{2}$, \\ Maung Maung Latt ${ }^{3}$, Win Khaing Moe ${ }^{2}$ \\ ${ }^{1}$ Department of Electronic Engineering, Yangon Technological University, Yangon, Republic of the Union of Myanmar \\ ${ }^{2}$ Department of Electrical and Electronic Engineering, Institute of Research and Innovation, Yangon, Republic of the Union of Myanmar \\ ${ }^{3}$ Department of Electronic Engineering, Technological University (Taungoo), Taungoo, Republic of the Union of Myanmar
}

\section{Email address:}

hlamyotun@ytu.edu.mm(H. M. Tun),dawthidathan@gmail.com(T. Than),myintmyintthan.ec@gmail.com (M. M. Than), khinsandartun91@gmail.com(K. S. Tun),drzaw290615@gmail.com(Z. M. Naing),mgmglatt2020@gmail.com (M. M. Latt), winkmoe@gmail.com (W.K. Moe)

\section{To cite this article:}

Hla Myo Tun, Thida Than, Myint Myint Than, Khin Sandar Tun, Zaw Min Naing, Maung Maung Latt, Win Khaing Moe. Analysis on Research and Education for Electromagnetic-Applied Subjects with Finite Difference Time Domain Theory. American Journal of Electromagnetics and Applications. Vol. 6, No. 1, 2018, pp. 6-16. doi: 10.11648/j.ajea.20180601.12

Received: February 16, 2018; Accepted: March 7, 2018; Published: March 29, 2018

\begin{abstract}
The paper presents the analysis on research and development purposes and education purposes for engineering electromagnetic applied subjects like Engineering Electromagnetic, Optoelectronics, and Semiconductor Physics by utilizing the Finite Difference Time Domain (FDTD) Techniques. FDTD technique is a powerful tool for understanding the nature of electromagnetic fields and their various applications for research and development purposes.
\end{abstract}

Keywords: Research and Development, Education Purposes, Engineering Electromagnetic, Finite Difference Time Domain Technique, Research University, MATLAB

\section{Introduction}

Yangon Technological University (former Yangon Institute of Technology (YIT) or Rangoon Institute of Technology (RIT)) plays a vital role in centre of excellence (COE) for advancement of engineering education in Myanmar. There are various engineering courses under the umbrella of Yangon Technological University ((YTU). Among them, the Department of Electronic Engineering is one of the best engineering disciplines at YTU. YTU offers the six-year course for all engineering disciplines to enhance the engineering education in Myanmar. At present, all courses are followed by the credit system which is the advanced education system in the world. The purposes, mission and vision of YTU focus only on the establishment of YTU to be one of theResearch Universities among other research universities all over the world. The target ofResearch University is followed the activities of research groups at university. Figure 1 shows the important activities of research group at YTU. The research publications are one of the credits for establishment of Research University.

The curriculum and syllabus of Electronic Engineering courses have been designed based on the curriculum and syllabus systems especially in Electronic Engineering from the numerous prestigious universities all over the world. There are five main specialized subjects under the Department of Electronic Engineering. They are Semiconductor Electronics, Communication Engineering, Control Engineering, Signal Processing Engineering, and Electronic Circuit Design Engineering with Embedded System [1].

In this paper, we report on the analysis of the research and education purposes for Engineering Electromagnetic applied subjects by applying the Finite Difference Time Domain technique under the division of Communication Engineering. The communication engineering division plays a crucial role in enhancement of Communication Technologies like 
Telecommunication Systems, Wireless Communication System, Mobile Communication Systems, and RF and Microwave Engineering under the Department of Electronic Engineering. Among them RF and Microwave Technology is very important and very fundamental technology to develop the modern communication systems. The RF and Microwave Engineering subject is supported by the Engineering Electromagnetic subject because the fundamental concepts on electric field and magnetic field theories and applications. The details discussion on the application of FDTD techniques in Electromagnetic applied subjects will be in the next sections [2-5].

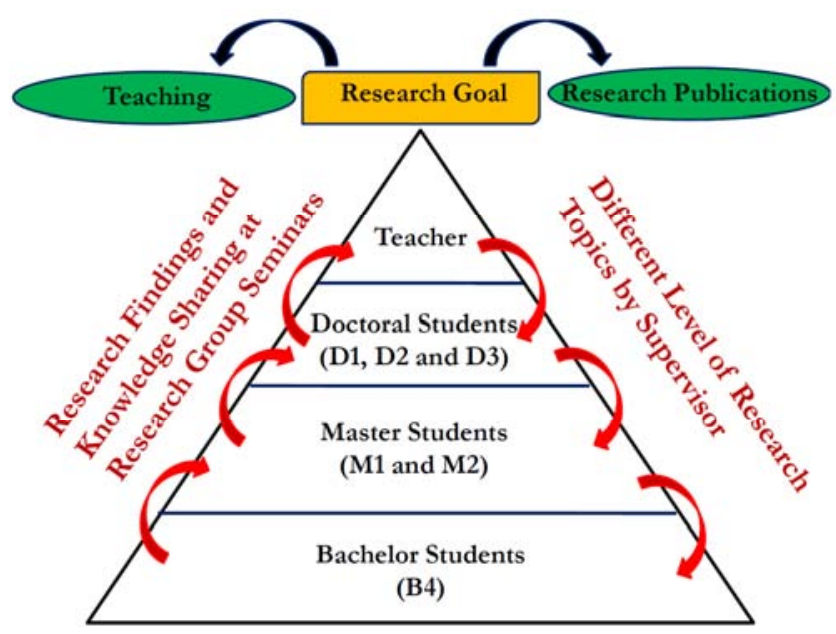

Figure 1. Formulation of Research Group Activities at YTU [1].

The rest of the organizations of the paper are as follows. Section II gives the two portions of overall curriculum map for the Electronic Engineering courses. Section III describes the discussion on Engineering Electromagnetic related subjects with FDTD techniques. Section IV mentions the talk with Semiconductor Electronics related subjects with FDTD Techniques. Section V presents the effects on the FDTD techniques for advanced research works under the Department of Electronic Engineering. Section VI demonstrates the experimental results on FDTD techniques for Electromagnetic applied subjects. Section VII gives the concluding remarks and further discussions on the effects of FDTD techniques for engineering education purposes.

\section{Two Portions of Overall Curriculum Maps}

The overall curriculum map has been developed by Enhancement of Engineering Higher Education Project under Japan International Cooperation Agency in 2013. The details curriculum map composes of five specialization courses of the Department of Electronic Engineering.

\subsection{Semiconductor Electronics Courses}

The important course under the Department of Electronic Engineering is Semiconductor Electronics. There are two main areas focus on the semiconductor electronic courses for undergraduate program. They are Physical Electronics and Applied Electronics. Figure 2 shows the classification of Electronic Engineering courses. The applied electronics like Microelectronic Circuit subjects have been conducted for undergraduate and graduate courses under the Department of Electronic Engineering. The Applied Electronicssubjects have been familiar with Electronic Engineering students of YTU since 1960. The Physical Electronics was not familiar with most Electronic Engineering students of YTU. The EEHE project has been established at YTU in 2013 and the advisor of EEHE project suggested to teach the Semiconductor related subjects and do research in Semiconductor Electronics for department development plan in 2013. According to the developed curriculum and syllabus for Semiconductor Electronics, the following subjects have to be learnt by Electronic Engineering Students at YTU. They are:

1. Materials for Electronics

2. Semiconductor Physics

3. Semiconductor Devices

4. Semiconductor Processes

These subjects have to be learnt by second year, third year, fourth year and fifth year courses of Electronic Engineering students.

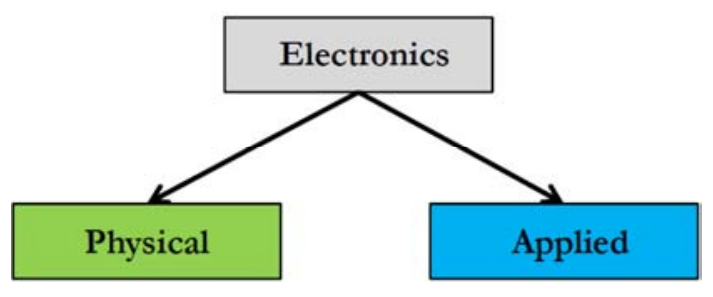

Figure 2. Classification for Electronic Engineering Courses.

\subsection{Communication Engineering Courses}

Another important subject under the Department of Electronic Engineering is Communication Engineering related subjects. For the Communication Engineering purposes, there are two portions to accomplish the target of Communication Engineering related specialization. Communication System Design and Communication Theory are two classes of Communication Engineering under the Department of Electronic Engineering of YTU. According to the developed curriculum and syllabus for Communication Engineering, the following subjects have to be learnt by Electronic Engineering Students at YTU. For the Communication Theory portion, the students have to learn the following subjects.

1. Analog and Digital Communication (Fundamental Communication)

2. Data Communication

3. Modern Communication System

For the Communication Theory portions, the students have to learn the following subjects.

1. Engineering Electromagnetic

2. Electromagnetic Waves and Theory 
3. Modern Communication System

These subjects have to be learnt by third year, fourth year and fifth year courses of Electronic Engineering students.

\section{Engineering Electromagnetic with FDTD}

Traditionally, the course designers from YTU have developed the curriculum and syllabus based on the advancement of modern technologies day-by-day. The important concept for preparing the courses on Engineering Electromagnetic related subjects based on the famous text books used in prestigious universities like Massachusetts Institute of Technology (MIT). The ideas behind the structure design for Engineering Electromagnetic is followed by the details mention objectives.

Understand the big ideas of electromagnetic, including:

1. Static and dynamic electromagnetic (EM) fields, energy, and power

2. EM fields and waves within and at the boundaries of media

3. EM radiation and propagation in space and within transmission lines

4. Circuit behaviour of simple EM devices and transmission lines

5. EM forces on charges, currents, and materials; mechanically produced fields

6. Photon behaviour

In support of these objectives, students will understand and calculate EM fields and key physical parameters for:

1. Fields and energies in simple planar, cylindrical, and spherical geometries

2. Fields within conducting, anisotropic, and plasma media

3. Resistors, capacitors, inductors, transformers, transmission lines, and resonators

4. Electric and magnetic forces on charges, wires, and media

5. Electric and magnetic motors and sensor/generators

6. Sinusoids and transients on TEM lines with mismatched impedances and tuning

7. EM fields at planar boundaries and within waveguides, including evanescence

8. Wireless and wired systems for communicating at $\mathrm{R}$ bits/second

9. Wire, aperture, and array antennas for transmission and reception

10. Simple photonic and acoustic devices

\subsection{Ideas Behind Traditional Course Design}

The concept of the Mathematical Foundations for Electromagnetic Theory is very fundamental courses for traditional course design but it is very important for Electronic Engineering students. The traditional techniques for learning that subjects are based only on the theoretical approach. The students cannot easily understand the fundamental concept very well. They have to emphasize to understand the fundamental concept based on the mathematical expression like Maxwell's equations or something like that. The lecturer could not support any materials for fulfilment of the teaching methods but they could only give the demonstration of the concept by using training kit. It is difficult to explain the fundamental concept because the electric field and magnetic field cannot be easily display on the blackboard or whiteboard in the classes. That teaching methods could not fully support for research purposes because the researchers have to understand fundamental concept very well and then they can do something. Table 1 gives the analysed data on effect of none simulation tools used in Electromagnetic applied subjects.

Table 1. Analysed Data on Effect of None Simulation Tools Used in Electromagnetic Applied Subjects.

\begin{tabular}{|c|c|c|c|}
\hline \multirow{2}{*}{ No } & \multicolumn{3}{|l|}{ Yangon Technological University } \\
\hline & Subject & Concentration Percentage & Accuracy of Understanding \\
\hline 1 & Engineering Electromagnetic & $72 \%$ & $75 \%$ \\
\hline 2 & Electromagnetic Waves and Theory & $74 \%$ & $78 \%$ \\
\hline 3 & Fundamental Communication & $71 \%$ & $74 \%$ \\
\hline 4 & Data Communication & $70 \%$ & $73 \%$ \\
\hline 5 & Modern Communication System & $70 \%$ & $73 \%$ \\
\hline
\end{tabular}

\subsection{Ideas for Modern Course Design with FDTD Simulation}

Based on the aforementioned data, the lecturer changed the teaching style for understanding on Engineering Electromagnetic applied subjects like communication theory based on advanced simulation tools. The Finite Difference Time Domain (FDTD) technique is the most powerful technique for making the understanding the concept of electromagnetic field and others.

The theory applied to learn the understanding the concept of electromagnetic field is very important for electronic engineers. After changing the methodology for teaching purposes, the analyses based on using the FDTD technique in the electromagnetic applied subjects have been performed.

Table 2 gives the predicted data on the effect of simulation tools like FDTD method used in Electromagnetic applied subject. These data pointed out the fully understanding on the subject and the accuracy of understanding is higher than the previous one. 
Table 2. Predicted Data on Effect of Simulation Tools Used in Electromagnetic Applied Subjects.

\begin{tabular}{llll}
\hline \multirow{2}{*}{ No } & Yangon Technological University & & \\
\cline { 2 - 4 } & Subject & Concentration Percentage & Accuracy of Understanding \\
\hline 1 & Engineering Electromagnetic & $100 \%$ & $98 \%$ \\
2 & Electromagnetic Waves and Theory & $100 \%$ & $98 \%$ \\
3 & Fundamental Communication & $100 \%$ & $98 \%$ \\
4 & Data Communication & $100 \%$ & $98 \%$ \\
5 & Modern Communication System & $100 \%$ & $98 \%$ \\
\hline
\end{tabular}

\section{Semiconductor Electronics with FDTD}

Conventionally, the course designers for semiconductor engineering from YTU have improved the curriculum and syllabus based on the encroachment of contemporary technologies step-by-step. The significantidea for arranging the courses on Semiconductor Engineering applied subjects based on the well-known text books used in high-status universities like Massachusetts Institute of Technology (MIT). The ideas behind the structure design for Semiconductor Engineering is followed by the details mention objectives.

Understand the big ideas of Semiconductor Electronics, including:

1. Materials in Electronics

2. Mathematics for Electronic Engineers

3. Semiconductor Physics

4. Quantum Electronics

5. Semiconductor Devices

6. Optoelectronic Measurement on Optical, Electronics and Magnetic Properties

7. Semiconductor Processes

8. Device Fabrication

In support of these objectives, students will understand and calculate Semiconductor Devices with their measurement techniques and key physical parameters for:

1. Crystal Structure

2. Properties of Materials

3. Mathematical Modelling of Semiconductor Materials

4. Maxell's Equations and Schrödinger Equation for Quantum Mechanics

5. Semiconductor Devices Structure and Band Structure Engineering
6. Optoelectronic and Measurement on Phonon Measurements, IR Measurement, Spintronics and TRPL Measurement

7. Crystal Growth with CVD, Mist-CVD, MOSVD, MBE etc

8. Optical Characteristics Measurement

9. Analyse the Device Performance

10. Analyse the Various properties on the developed semiconductor devices

11. Semiconductor Manufacturing Process

\subsection{Ideas Behind Traditional Course Design}

The concept of the Physics for Semiconductor Electronics and Quantum Mechanics are very essential courses for conventional course design but it is very important for Electronic Engineering students. The established techniques for learning that subjects are based only on the theoretical approach. The students cannot effortlessly recognize the primary concept very well. They have to accentuate to realize the primary concept based on the mathematical expression like Maxwell's equations, Schrödinger Equation or something like that. The lecturer could not sustain any resources for fulfilment of the teaching technique but they could only give the demonstration of the concept by using simple experiment. It is complicated to make clear the primary concept because the semiconductor physics and theories are cannot be easily demonstrated on the blackboard or whiteboard in the classes. That teaching technique could not completely support for research purposes because the researchers have to understand original concept very well and then they can do something for their research works. Table 3 gives the analysed data on effect of none simulation tools used in Semiconductor Electronics applied subjects [6-10].

Table 3. Analysed Data on Effect of None Simulation Tools Used in Semiconductor Electronics Applied Subjects.

\begin{tabular}{llll}
\hline \multirow{2}{*}{ No } & Yangon Technological University & & \\
\cline { 2 - 4 } & Subject & Concentration Percentage & Accuracy of Understanding \\
\hline 1 & Materials in Electronics & $71 \%$ & $76 \%$ \\
2 & Semiconductor Physics & $73 \%$ & $77 \%$ \\
3 & Semiconductor Devices & $75 \%$ & $79 \%$ \\
4 & Optoelectronics & $74 \%$ & $78 \%$ \\
5 & Semiconductor Fabrication and Processes & $70 \%$ & $75 \%$ \\
\hline
\end{tabular}

\subsection{Ideas for New Course Design with FDTD Simulation}

According to the above mentioned statistics, the lecturer changed the teaching style for understanding on Semiconductor Engineering applied subjects like Semiconductor Measurements based on sophisticated simulation tools. The Finite Difference Time Domain (FDTD) technique is the most dominant practice for making the understanding the concept of measurement on semiconductor materials field and others. 
Table 4. Predicted Data on Effect of Simulation Tools Used in Semiconductor Electronics Applied Subjects.

\begin{tabular}{llll}
\hline \multirow{2}{*}{ No } & Yangon Technological University & Concentration Percentage & Accuracy of Understanding \\
\cline { 2 - 4 } & Subject & $100 \%$ & $98 \%$ \\
\hline 1 & Materials in Electronics & $100 \%$ & $98 \%$ \\
2 & Semiconductor Physics & $100 \%$ & $98 \%$ \\
3 & Semiconductor Devices & $100 \%$ & $98 \%$ \\
4 & Optoelectronics & $98 \%$ \\
5 & Semiconductor Fabrication and Processes & $100 \%$ & $98 \%$ \\
\hline
\end{tabular}

The hypothesis applied to gain knowledge of the understanding on concept of semiconductor electronic measurement is very important for electronic engineers. After altering the method for teaching purposes, the analyses based on using the FDTD technique in the semiconductor measurement applied subjects have been completed.

Table 4 gives the predicted data on the effect of simulation tools like FDTD method used in Semiconductor Electronics applied subject. These data highlighted the effusive understanding on the subject and the accuracy of understanding is higher than the earlier one.

\section{Effects on the FDTD Techniques for Advanced Research Works}

Finite-Difference Time-Domain (FDTD) method is a recognized practice for the investigation of quantum devices in semiconductor technology for research purposes [11]. That practice can solve a discretized Schrödinger equation in an iterative progression. Nevertheless, the technique offers only a second-order exact numerical clarification and needs that the spatial grid size and time step should convince a very limited condition in order to avert the numerical clarification from diverging. The details description on FDTD technique is discussed in the following sections. The approximating the time derivatives is given.

An intuitive first guess at approximating the time derivatives in Maxwell's Equation is

$$
\begin{gathered}
\nabla \times \overline{\mathrm{E}}(\mathrm{t})=-\mu \frac{\partial \overline{\mathrm{H}}(\mathrm{t})}{\partial \mathrm{t}} \Rightarrow \nabla \times \overline{\mathrm{E}}(\mathrm{t}) \cong-\mu \frac{\overline{\mathrm{H}}(\mathrm{t}+\Delta \mathrm{t})-\overline{\mathrm{H}}(\mathrm{t})}{\Delta \mathrm{t}} \\
\nabla \times \overline{\mathrm{H}}(\mathrm{t})=\varepsilon \frac{\partial \overline{\mathrm{E}}(\mathrm{t})}{\partial \mathrm{t}} \Rightarrow \nabla \times \overline{\mathrm{H}}(\mathrm{t}) \cong \varepsilon \frac{\overline{\mathrm{E}}(\mathrm{t}+\Delta \mathrm{t})-\overline{\mathrm{E}}(\mathrm{t})}{\Delta \mathrm{t}}
\end{gathered}
$$

We adjust the finite difference equations so that each term exists at the same point in time.

$$
\begin{aligned}
& \nabla \times \overline{\mathrm{E}}(\mathrm{t})=-\mu \frac{\partial \overline{\mathrm{H}}(\mathrm{t})}{\partial \mathrm{t}} \Rightarrow \nabla \times \overline{\mathrm{E}}(\mathrm{t})=-\mu \frac{\overline{\mathrm{H}}\left(\mathrm{t}+\frac{\Delta \mathrm{t})}{2}\right)-\overline{\mathrm{H}}\left(\mathrm{t}-\frac{\Delta \mathrm{t}}{2}\right)}{\Delta \mathrm{t}} \\
& \nabla \times \overline{\mathrm{H}}(\mathrm{t})=\varepsilon \frac{\partial \overline{\mathrm{E}}(\mathrm{t})}{\partial \mathrm{t}} \Rightarrow \nabla \times \overline{\mathrm{H}}\left(\mathrm{t}+\frac{\Delta \mathrm{t}}{2}\right)=\varepsilon \frac{\overline{\mathrm{E}}(\mathrm{t}+\Delta \mathrm{t})-\overline{\mathrm{E}}(\mathrm{t})}{\Delta \mathrm{t}}
\end{aligned}
$$

These equations will get messy if we include interpolations.

We stagger $\mathrm{E}$ and $\mathrm{H}$ in time so that $\mathrm{E}$ exists at integer time steps $(0, \Delta \mathrm{t}, 2 \Delta \mathrm{t}, \ldots)$ and $\mathrm{H}$ exists at half time steps $(\Delta \mathrm{t} / 2$, $\mathrm{t}+\Delta \mathrm{t} / 2,2 \mathrm{t}+\Delta \mathrm{t} / 2, \ldots)$

$$
\begin{aligned}
& \left.\overline{\mathrm{H}}\right|_{\mathrm{t}+\frac{\Delta \mathrm{t}}{2}}=\left.\overline{\mathrm{H}}\right|_{\mathrm{t}-\frac{\Delta \mathrm{t}}{2}-\frac{\Delta \mathrm{t}}{\mu}}\left(\nabla \times\left.\overline{\mathrm{E}}\right|_{\mathrm{t}}\right) \\
& \left.\overline{\mathrm{E}}\right|_{\mathrm{t}+\Delta \mathrm{t}}=\left.\overline{\mathrm{E}}\right|_{\mathrm{t}}+\frac{\Delta \mathrm{t}}{\varepsilon}\left(\nabla \times\left.\overline{\mathrm{H}}\right|_{\mathrm{t}+\frac{\Delta \mathrm{t}}{2}}\right)
\end{aligned}
$$

We will handle the spatial derivatives in $\nabla \times$ next lecture in a very similar manner. Figure 3 shows the fundamental algorithm for FDTD technique.

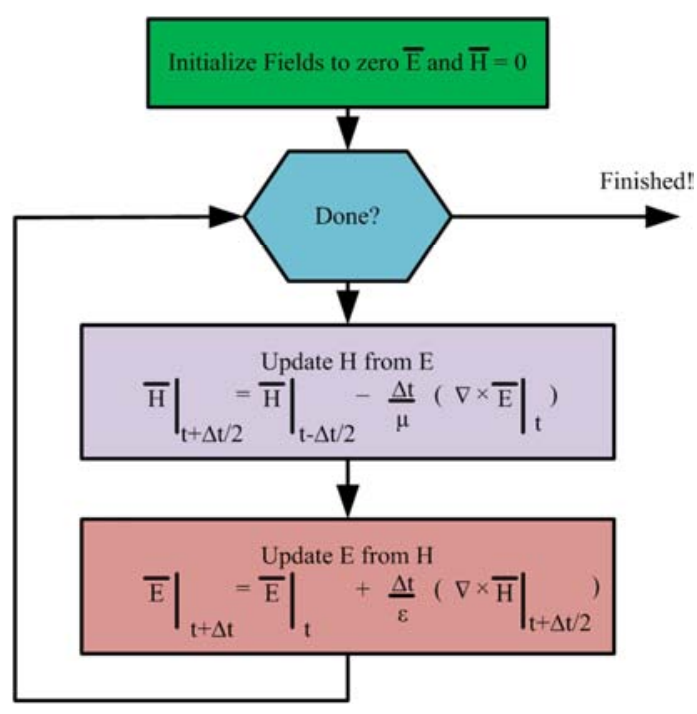

Figure 3. FDTD Algorithm.

Assume Only Diagonal Tensors

$$
\begin{aligned}
& \frac{\partial \mathrm{E}_{\mathrm{z}}}{\partial \mathrm{y}}-\frac{\partial \mathrm{E}_{\mathrm{y}}}{\partial \mathrm{z}}=-\frac{1}{\mathrm{C}_{0}}\left[\boldsymbol{\mu}_{\mathbf{x x}} \frac{\partial \overline{\mathbf{H}}_{\mathbf{x}}}{\partial \mathbf{t}}+\mu_{\mathrm{xy}} \frac{\partial \overline{\mathrm{H}}_{\mathrm{y}}}{\partial \mathrm{t}}+\mu_{\mathrm{xz}} \frac{\partial \overline{\mathrm{H}}_{\mathrm{z}}}{\partial \mathrm{t}}\right] \\
& \nabla \times \overline{\mathrm{E}}=\frac{\left[\mu_{\mathrm{r}}\right]}{\mathrm{C}_{0}} \frac{\partial \overline{\mathrm{H}}}{\partial \mathrm{t}} \Rightarrow \frac{\partial \mathrm{E}_{\mathrm{x}}}{\partial \mathrm{z}}-\frac{\partial \mathrm{E}_{\mathrm{z}}}{\partial \mathrm{x}}=-\frac{1}{\mathrm{C}_{0}}\left[\mu_{\mathrm{yx}} \frac{\partial \overline{\mathrm{H}}_{\mathrm{x}}}{\partial \mathrm{t}}+\boldsymbol{\mu}_{\mathbf{y y}} \frac{\partial \overline{\mathbf{H}}_{\mathbf{y}}}{\partial \mathrm{t}}+\mu_{\mathrm{yz}} \frac{\partial \overline{\mathrm{H}}_{\mathrm{z}}}{\partial \mathrm{t}}\right] \\
& \frac{\partial \mathrm{E}_{\mathrm{y}}}{\partial \mathrm{x}}-\frac{\partial \mathrm{E}_{\mathrm{x}}}{\partial \mathrm{y}}=-\frac{1}{\mathrm{C}_{0}}\left[\mu_{\mathrm{zx}} \frac{\partial \overline{\mathrm{H}}_{\mathrm{x}}}{\partial \mathrm{t}}+\mu_{\mathrm{zy}} \frac{\partial \overline{\mathrm{H}}_{\mathrm{y}}}{\partial \mathrm{t}}+\boldsymbol{\mu}_{\mathrm{zz}} \frac{\partial \overline{\mathbf{H}}_{\mathbf{z}}}{\partial \mathrm{t}}\right] \\
& \frac{\partial \mathrm{H}_{\mathrm{z}}}{\partial \mathrm{y}}-\frac{\partial \mathrm{H}_{\mathrm{y}}}{\partial \mathrm{z}}=+\frac{1}{\mathrm{C}_{0}}\left[\boldsymbol{\varepsilon}_{\mathbf{x x}} \frac{\partial \overline{\mathbf{E}}_{\mathbf{x}}}{\partial \mathbf{t}}+\varepsilon_{\mathrm{xy}} \frac{\partial \overline{\mathrm{E}}_{\mathrm{y}}}{\partial \mathrm{t}}+\varepsilon_{\mathrm{xz}} \frac{\partial \overline{\mathrm{E}}_{\mathrm{z}}}{\partial \mathrm{t}}\right] \\
& \nabla \times \overline{\mathrm{H}}=\frac{\left[\varepsilon_{\mathrm{r}}\right]}{\mathrm{C}_{0}} \frac{\partial \overline{\mathrm{E}}}{\partial \mathrm{t}} \Rightarrow \frac{\partial \mathrm{H}_{\mathrm{x}}}{\partial \mathrm{z}}-\frac{\partial \mathrm{H}_{\mathrm{z}}}{\partial \mathrm{x}}=+\frac{1}{\mathrm{C}_{0}}\left[\varepsilon_{\mathrm{yx}} \frac{\partial \overline{\mathrm{E}}_{\mathrm{x}}}{\partial \mathrm{t}}+\boldsymbol{\varepsilon}_{\mathbf{y y}} \frac{\partial \overline{\mathbf{E}}_{\mathbf{y}}}{\partial \mathrm{t}}+\varepsilon_{\mathrm{yz}} \frac{\partial \overline{\mathrm{E}}_{\mathrm{z}}}{\partial \mathrm{t}}\right] \\
& \frac{\partial \mathrm{H}_{\mathrm{y}}}{\partial \mathrm{x}}-\frac{\partial \mathrm{H}_{\mathrm{x}}}{\partial \mathrm{y}}=+\frac{1}{\mathrm{C}_{0}}\left[\varepsilon_{\mathrm{zx}} \frac{\partial \overline{\mathrm{E}}_{\mathrm{x}}}{\partial \mathrm{t}}+\varepsilon_{\mathrm{zy}} \frac{\partial \overline{\mathrm{E}}_{\mathrm{y}}}{\partial \mathrm{t}}+\boldsymbol{\varepsilon}_{\mathbf{z z}} \frac{\partial \overline{\mathbf{E}}_{\mathbf{z}}}{\partial \mathrm{t}}\right]
\end{aligned}
$$

Final Analytical Equations are as follows:

$$
\begin{aligned}
& \frac{\partial \mathrm{E}_{\mathrm{z}}}{\partial \mathrm{y}}-\frac{\partial \mathrm{E}_{\mathrm{y}}}{\partial \mathrm{z}}=-\frac{\mu_{\mathrm{xx}}}{\mathrm{C}_{0}}\left[\frac{\partial \widetilde{\mathrm{H}}_{\mathrm{x}}}{\partial \mathrm{t}}\right] \\
& \frac{\partial \mathrm{E}_{\mathrm{x}}}{\partial \mathrm{z}}-\frac{\partial \mathrm{E}_{\mathrm{z}}}{\partial \mathrm{x}}=-\frac{\mu_{\mathrm{yy}}}{\mathrm{C}_{0}}\left[\frac{\partial \widetilde{\mathrm{H}}_{\mathrm{y}}}{\partial \mathrm{t}}\right] \\
& \frac{\partial \mathrm{E}_{\mathrm{y}}}{\partial \mathrm{x}}-\frac{\partial \mathrm{E}_{\mathrm{x}}}{\partial \mathrm{y}}=-\frac{\mu_{\mathrm{zz}}}{\mathrm{C}_{0}}\left[\frac{\partial \widetilde{\mathrm{H}}_{\mathrm{z}}}{\partial \mathrm{t}}\right]
\end{aligned}
$$




$$
\begin{aligned}
& \frac{\partial \widetilde{\mathrm{H}}_{\mathrm{z}}}{\partial \mathrm{y}}-\frac{\partial \widetilde{\mathrm{H}}_{\mathrm{y}}}{\partial \mathrm{z}}=+\frac{\varepsilon_{\mathrm{xx}}}{\mathrm{C}_{0}}\left[\frac{\partial \mathrm{E}_{\mathrm{x}}}{\partial \mathrm{t}}\right] \\
& \frac{\partial \widetilde{\mathrm{H}}_{\mathrm{x}}}{\partial \mathrm{z}}-\frac{\partial \widetilde{\mathrm{H}}_{\mathrm{z}}}{\partial \mathrm{x}}=+\frac{\varepsilon_{\mathrm{yy}}}{\mathrm{C}_{0}}\left[\frac{\partial \mathrm{E}_{\mathrm{y}}}{\partial \mathrm{t}}\right] \\
& \frac{\partial \widetilde{\mathrm{H}}_{\mathrm{y}}}{\partial \mathrm{x}}-\frac{\partial \widetilde{\mathrm{H}}_{\mathrm{x}}}{\partial \mathrm{y}}=+\frac{\varepsilon_{\mathrm{zz}}}{\mathrm{C}_{0}}\left[\frac{\partial \mathrm{E}_{\mathrm{z}}}{\partial \mathrm{t}}\right]
\end{aligned}
$$

The governing equations for finding the finite difference condition are mentioned in the following section. At first, the finite difference equations for $\mathrm{H}_{\mathrm{x}}, \mathrm{H}_{\mathrm{y}}$, and $\mathrm{H}_{\mathrm{z}}$ for magnetic field expressions. Figure. 4 to 6 show the details concept for magnetic field calculations from Maxwell's equations [12].

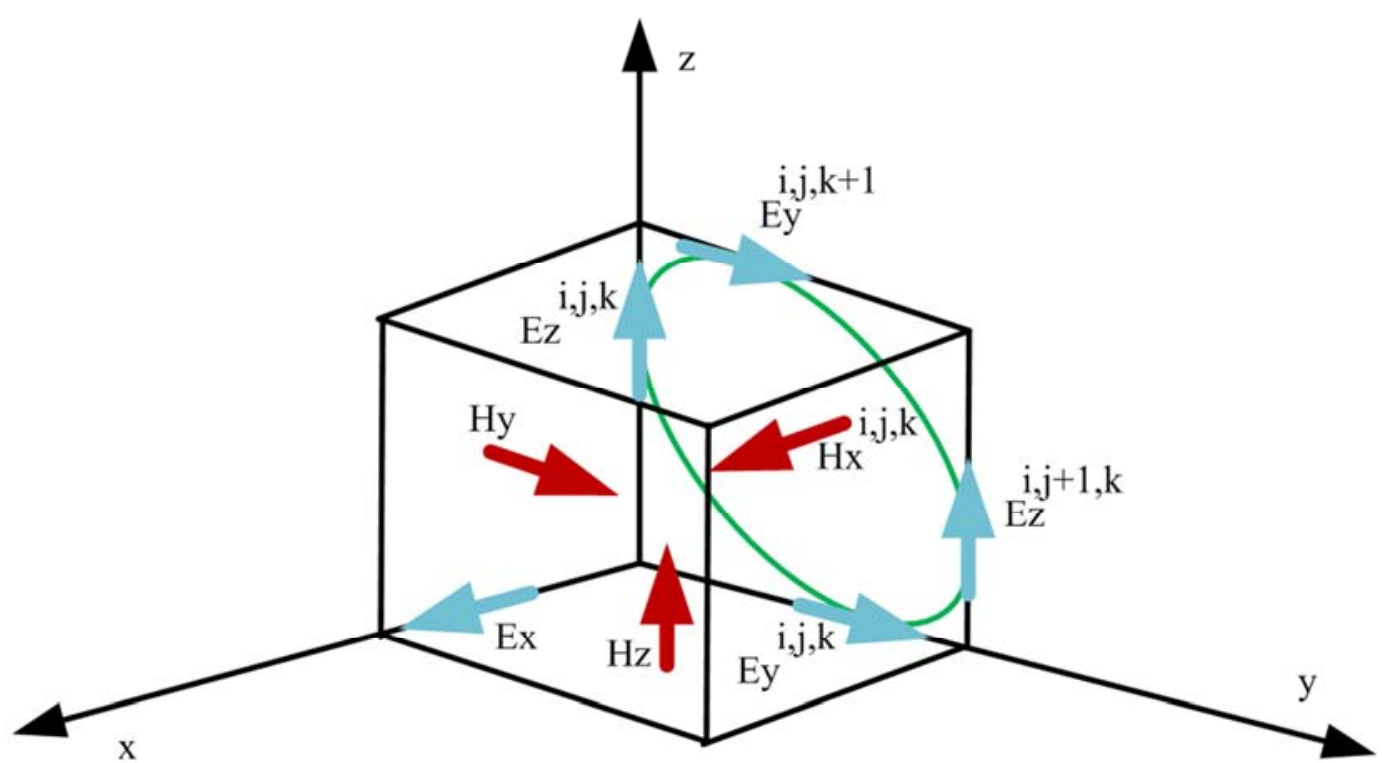

Figure 4. Finite Difference Equation for $H_{x}$.

$$
\begin{aligned}
& \frac{\partial \mathrm{E}_{\mathrm{z}}}{\partial \mathrm{y}}-\frac{\partial \mathrm{E}_{\mathrm{y}}}{\partial \mathrm{z}}=-\frac{\mu_{\mathrm{xx}}}{\mathrm{C}_{0}} \frac{\partial \widetilde{\mathrm{H}}_{\mathrm{x}}}{\partial \mathrm{t}} \\
& \frac{\left.\mathrm{E}_{\mathrm{z}}^{\mathrm{i}, \mathrm{j}+1, \mathrm{k}}\right|_{\mathrm{t}}-\left.\mathrm{E}_{\mathrm{z}}^{\mathrm{i}, \mathrm{j}, \mathrm{k}}\right|_{t}}{\Delta \mathrm{y}}-\frac{\left.\mathrm{E}_{\mathrm{y}}^{\mathrm{i}, \mathrm{j}, \mathrm{k}+1}\right|_{\mathrm{t}}-\left.\mathrm{E}_{\mathrm{y}}^{\mathrm{i}, \mathrm{j}, \mathrm{k}}\right|_{t}}{\Delta \mathrm{z}}=-\frac{\mu_{\mathrm{xx}}^{\mathrm{i}, \mathrm{k}, \mathrm{H}}}{\mathrm{C}_{0}} \frac{\left.\left.\widetilde{\mathrm{H}}_{\mathrm{x}}^{\mathrm{i}, \mathrm{j}, \mathrm{k}}\right|_{\mathrm{t}+\frac{\Delta \mathrm{t}}{2}} \widetilde{\mathrm{H}}_{\mathrm{x}}^{\mathrm{i}, \mathrm{j}, \mathrm{k}}\right|_{\mathrm{t}-\frac{\Delta \mathrm{t}}{2}}}{\Delta \mathrm{t}}
\end{aligned}
$$

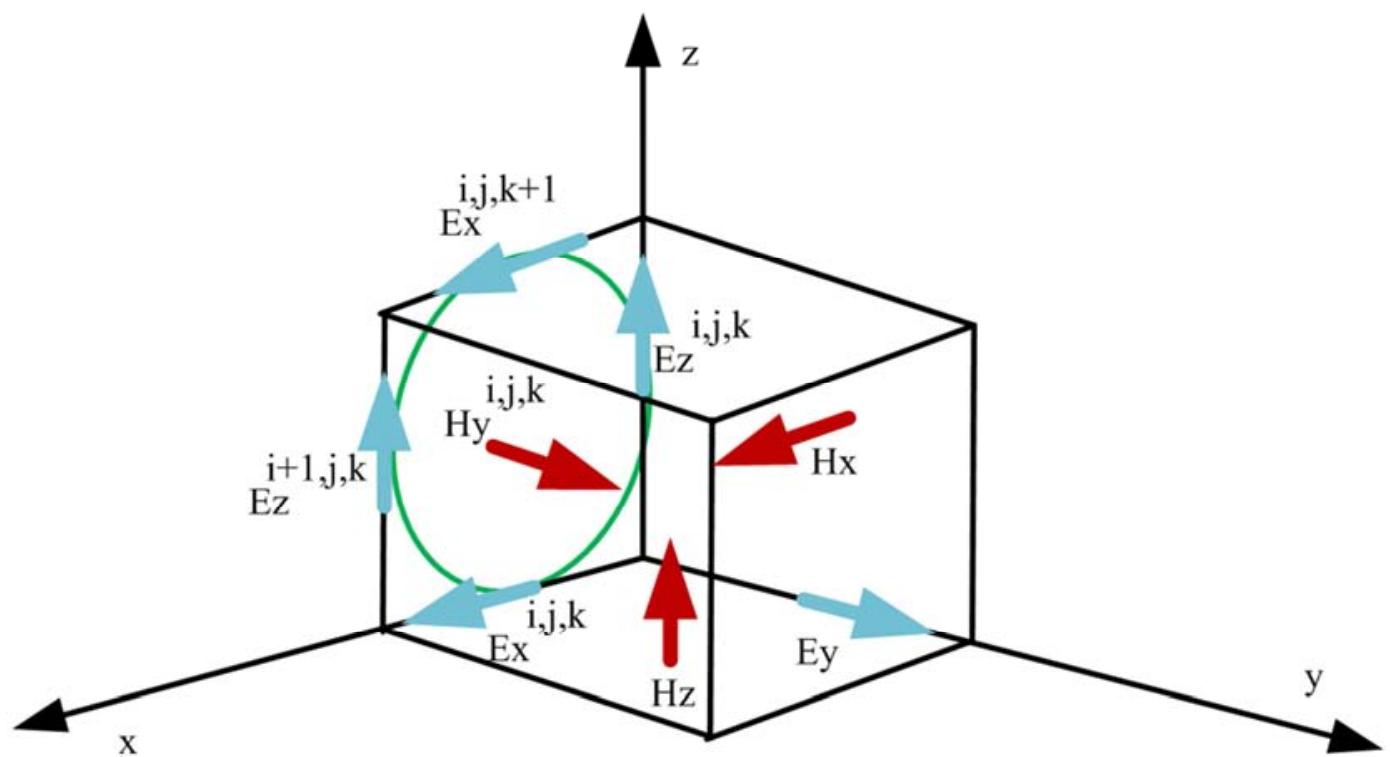

Figure 5. Finite Difference Equation for $H_{y}$.

$$
\begin{aligned}
& \frac{\partial \mathrm{E}_{\mathrm{x}}}{\partial \mathrm{z}}-\frac{\partial \mathrm{E}_{\mathrm{z}}}{\partial \mathrm{x}}=-\frac{\mu_{\mathrm{yy}}}{\mathrm{C}_{0}} \frac{\partial \widetilde{\mathrm{H}}_{\mathrm{y}}}{\partial \mathrm{t}}
\end{aligned}
$$

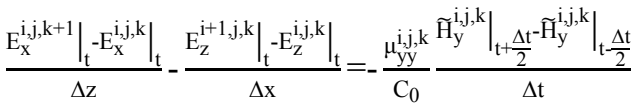




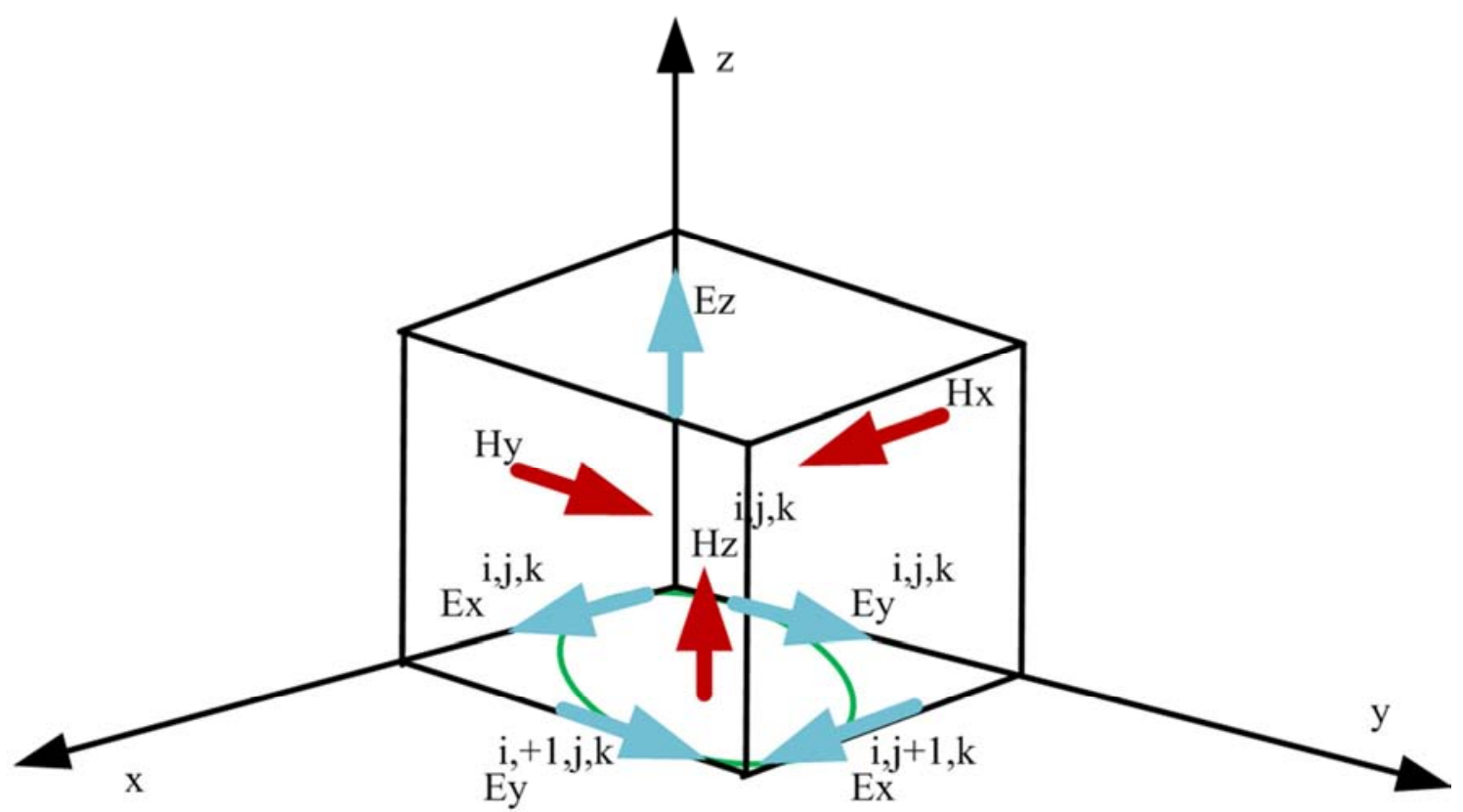

Figure 6. Finite Difference Equation for $H_{z}$.

$$
\begin{aligned}
& \frac{\partial \mathrm{E}_{\mathrm{y}}}{\partial \mathrm{x}}-\frac{\partial \mathrm{E}_{\mathrm{x}}}{\partial \mathrm{y}}=-\frac{\mu_{\mathrm{zz}}}{\mathrm{C}_{0}} \frac{\partial \widetilde{\mathrm{H}}_{\mathrm{z}}}{\partial \mathrm{t}}
\end{aligned}
$$

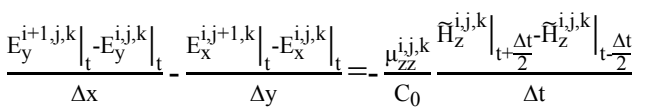

The second portion is to find the electric field expressions based on $\mathrm{E}_{\mathrm{x}}, \mathrm{E}_{\mathrm{y}}$, and $\mathrm{E}_{\mathrm{z}}$ from Maxwell's Equations.

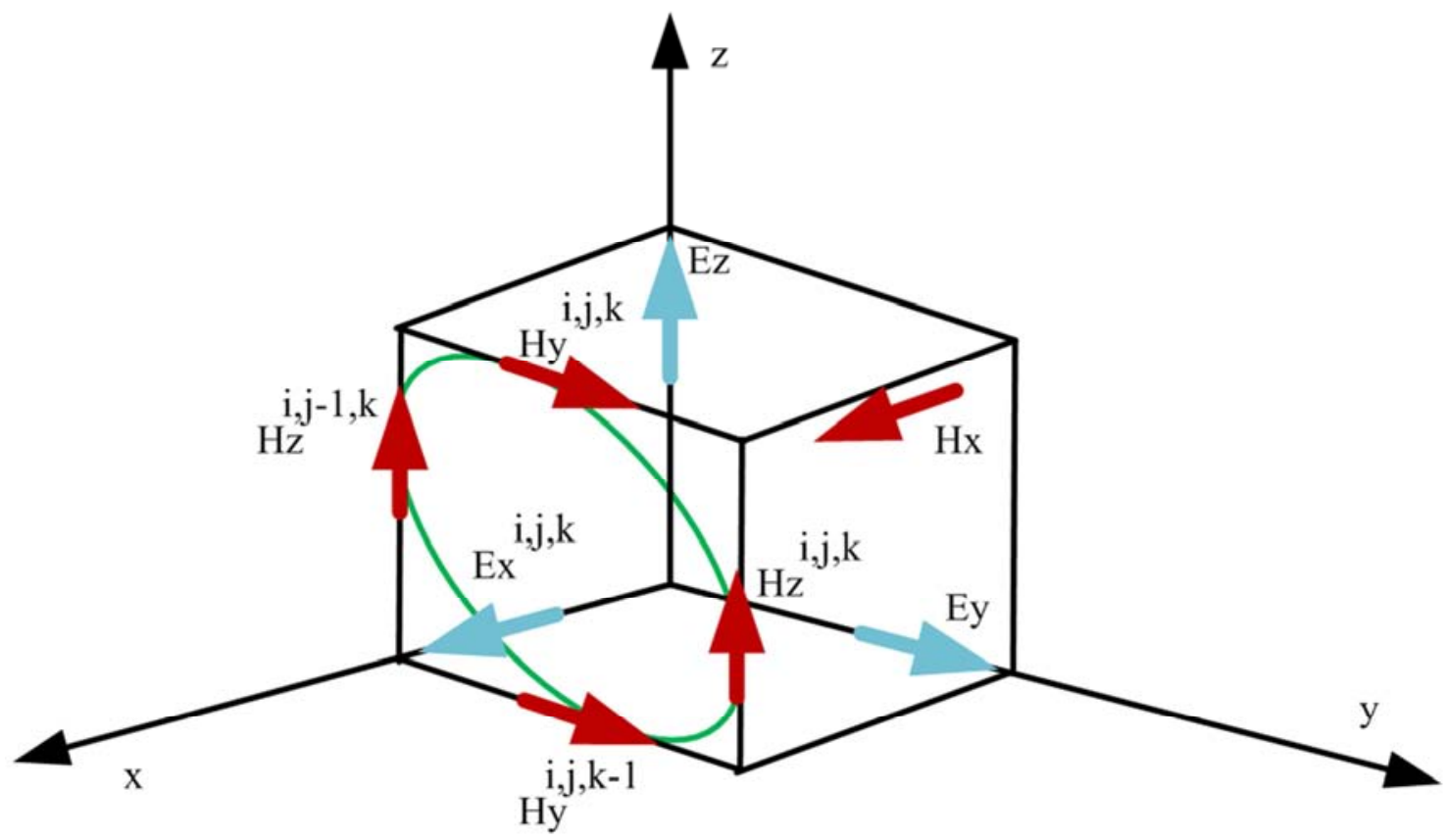

Figure 7. Finite Difference Equation for $E_{x}$.

$$
\begin{gathered}
\frac{\partial \widetilde{\mathrm{H}}_{\mathrm{z}}}{\partial \mathrm{y}}-\frac{\partial \widetilde{\mathrm{H}}_{\mathrm{y}}}{\partial \mathrm{z}}=\frac{\varepsilon_{\mathrm{xx}}}{\mathrm{C}_{0}} \frac{\partial \mathrm{E}_{\mathrm{x}}}{\partial \mathrm{t}} \\
\frac{\left.\widetilde{\mathrm{H}}_{\mathrm{z}}^{\mathrm{i}, \mathrm{j}, \mathrm{k}}\right|_{\mathrm{t}}-\left.\widetilde{\mathrm{H}}_{\mathrm{z}}^{\mathrm{i}, \mathrm{j}-1, \mathrm{k}}\right|_{\mathrm{t}}}{\Delta \mathrm{y}}-\frac{\left.\widetilde{\mathrm{H}}_{\mathrm{y}}^{\mathrm{i}, \mathrm{j}, \mathrm{k}}\right|_{\mathrm{t}}-\left.\widetilde{\mathrm{H}}_{\mathrm{y}}^{\mathrm{i}, \mathrm{j}, \mathrm{k}-1}\right|_{\mathrm{t}}}{\Delta \mathrm{z}}=\frac{\varepsilon_{\mathrm{xx}}^{\mathrm{i}, \mathrm{k} \mathrm{k}}}{\mathrm{C}_{0}} \frac{\left.\mathrm{E}_{\mathrm{x}}^{\mathrm{i}, \mathrm{j}, \mathrm{k}}\right|_{\mathrm{t}+\Delta \mathrm{t}}-\left.\mathrm{E}_{\mathrm{x}}^{\mathrm{i}, \mathrm{j}, \mathrm{k}}\right|_{\mathrm{t}}}{\Delta \mathrm{t}}
\end{gathered}
$$




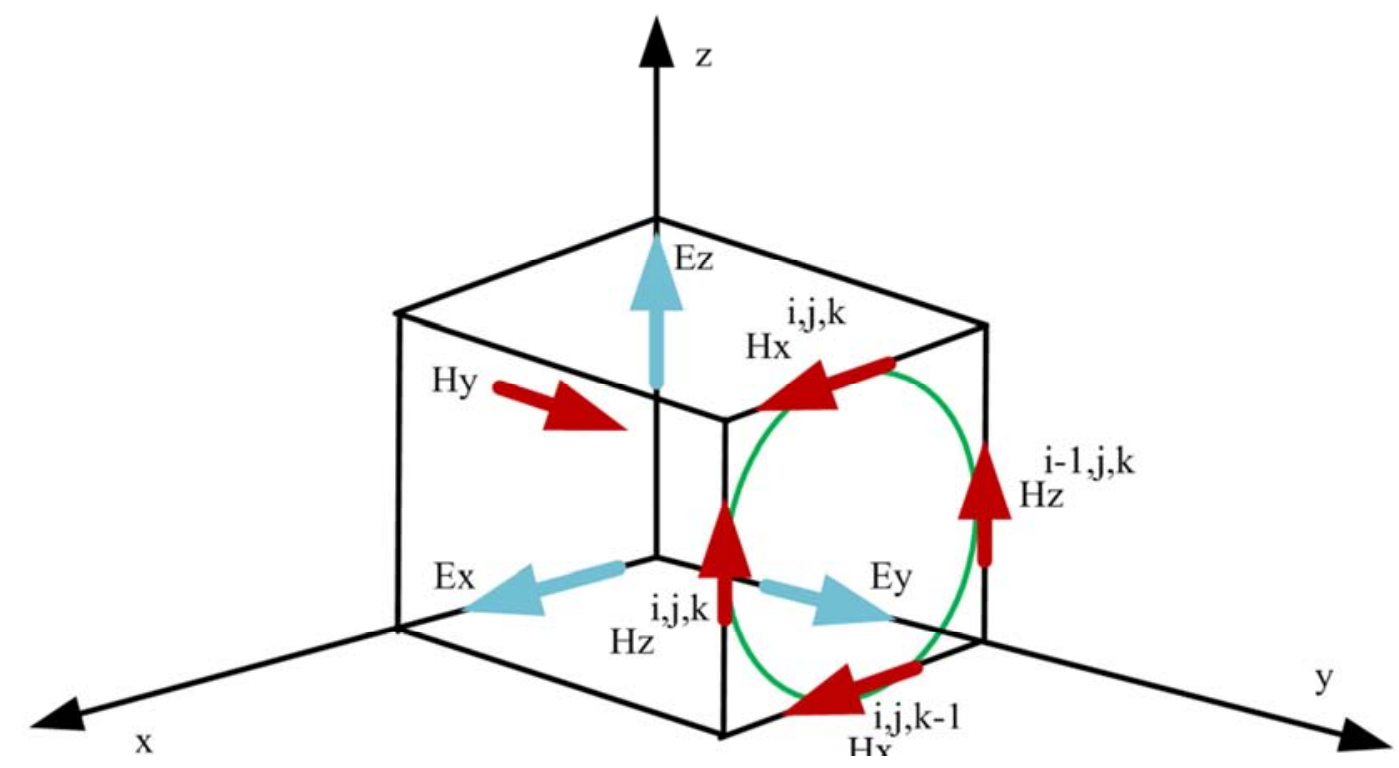

Figure 8. Finite Difference Equation for $E_{y}$.

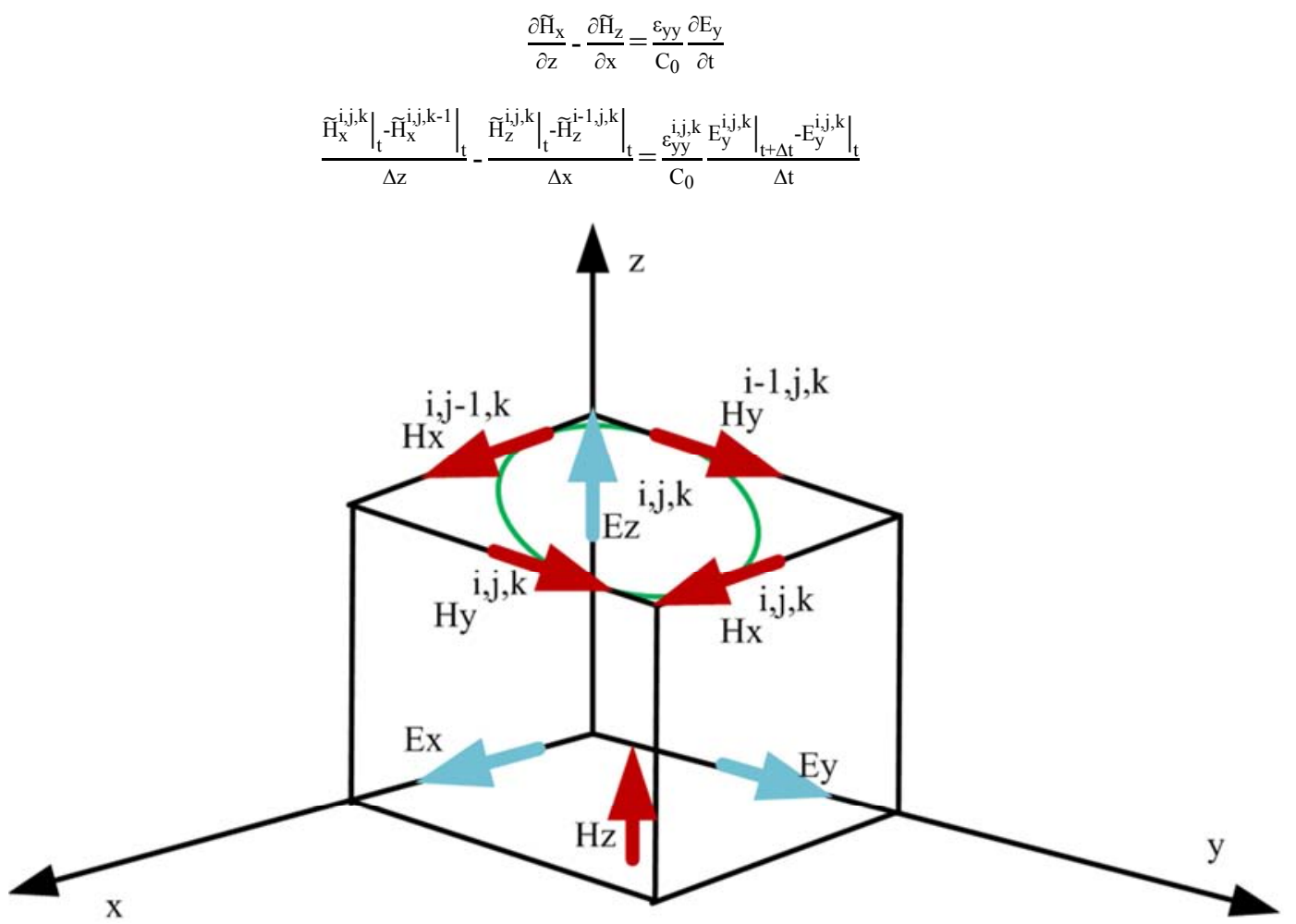

Figure 9. Finite Difference Equation for $E_{z}$.

$$
\begin{gathered}
\frac{\partial \widetilde{\mathrm{H}}_{\mathrm{y}}}{\partial \mathrm{x}}-\frac{\partial \widetilde{\mathrm{H}}_{\mathrm{x}}}{\partial \mathrm{y}}=\frac{\varepsilon_{\mathrm{zz}}}{\mathrm{C}_{0}} \frac{\partial \mathrm{E}_{\mathrm{z}}}{\partial \mathrm{t}} \\
\frac{\left.\widetilde{\mathrm{H}}_{\mathrm{y}}^{\mathrm{i}, \mathrm{k}, \mathrm{k}}\right|_{\mathrm{t}}-\left.\widetilde{\mathrm{H}}_{\mathrm{y}}^{\mathrm{i}-1, \mathrm{j}, \mathrm{k}}\right|_{\mathrm{t}}}{\Delta \mathrm{x}}-\frac{\left.\widetilde{\mathrm{H}}_{\mathrm{x}}^{\mathrm{i}, \mathrm{j}, \mathrm{k}}\right|_{\mathrm{t}}-\left.\widetilde{\mathrm{H}}_{\mathrm{x}}^{\mathrm{i}, \mathrm{j}-1, \mathrm{k}}\right|_{\mathrm{t}}}{\Delta \mathrm{y}}=\frac{\varepsilon_{\mathrm{zz}}^{\mathrm{i}, \mathrm{j}, \mathrm{k}}}{\mathrm{C}_{0}} \frac{\left.\mathrm{E}_{\mathrm{z}}^{\mathrm{i}, \mathrm{j}, \mathrm{k}}\right|_{\mathrm{t}+\Delta \mathrm{t}}-\left.\mathrm{E}_{\mathrm{z}}^{\mathrm{i}, \mathrm{j}, \mathrm{k}}\right|_{\mathrm{t}}}{\Delta \mathrm{t}}
\end{gathered}
$$

Based on these governing equations, the researchers could do their research works under the electromagnetic applied system by using FDTD technique. Most researchers could implement their simulation coding with the help of MATLAB for one dimensional, two dimensional and three dimensional purposes. The details development for coding for FDTD approaches could not be discussed in this section. We really realize that the effectiveness of the usage of FDTD method for postgraduate courses at YTU.

\section{Experimental Results on FDTD Techniques for Electromagnetic Applied Subjects}

There are two portions for analysing the FDTD techniques applied in Engineering Electromagnetic related subjects and 
Semiconductor Electronics related subjects with the help of MATLAB. According to the fundamental concept on FDTD technique, we could develop the MATLAB code for simulation purposes.

\subsection{Approaches for Electromagnetic Field Concepts}

Figure 10 shows the 1D FDTD simulations with perfectly matched layer boundary. The time steps for simulation are 1318 based on the calculated parameters for simulation. According to the results of 1D FDTD simulation, the students could easily understand the fundamental concept of the nature of electromagnetic field in the absorbing boundary condition in one dimensional point of view.

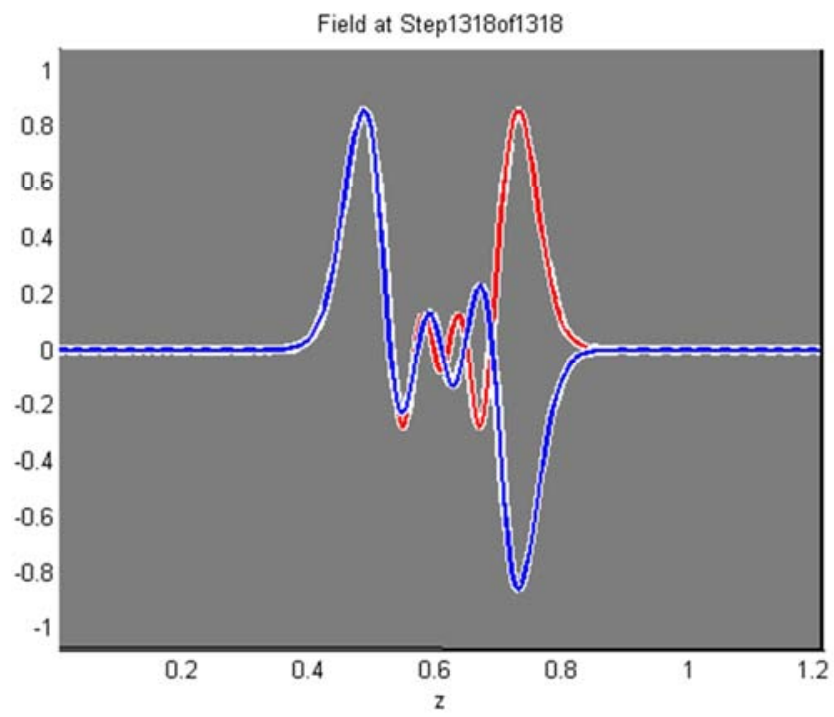

Figure 10. ID FDTD Simulation with Perfectly Matched Layer Boundary for Electromagnetic Field.

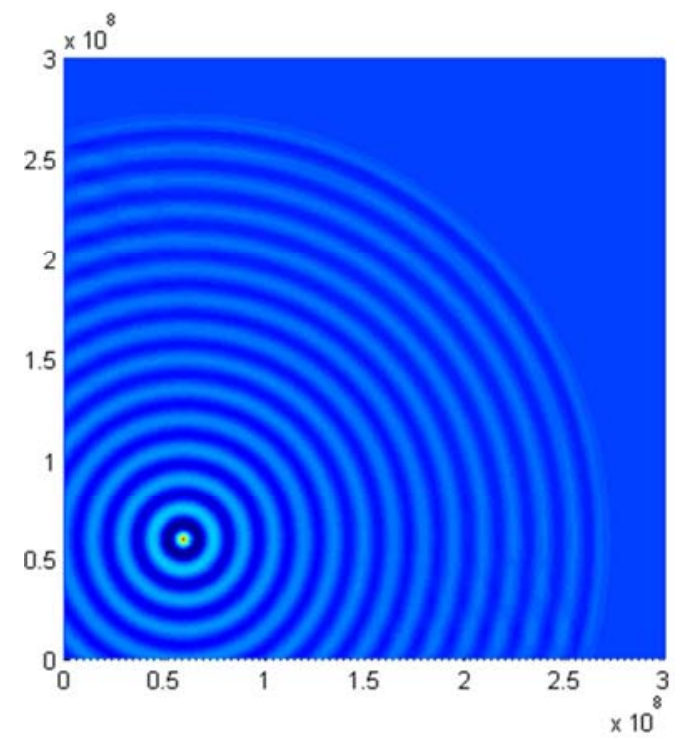

Figure 11. 2D FDTD Simulation with Perfectly Matched Layer Boundary for Electromagnetic Field.

Figure 11 shows the 2D FDTD result with perfectly matched layer boundary for Electromagnetic Filed simulation. The time steps for simulation are 1000 based on the calculated parameters for simulation. Based on the simulation results of $2 \mathrm{D}$ FDTD, the learners could effortlessly realize the concept of electromagnetic field in the PML boundary for visualization point of view. These results say the theoretical concepts of electromagnetic field could be understood well based on the simulation results or experimental results.

Figure 12 shows the 1D FDTD simulations with adding a device between the free space region for measurement of transmittance and reflectance for semiconductor material from optical purses source of laser. The time steps for simulation are 6770 based on the specific parameters from the simulation platform. The researchers could easily understand the concept of optical properties like transmittance and reflectance from the semiconductor devices.

\subsection{Approaches for Semiconductor Measurement Concepts}
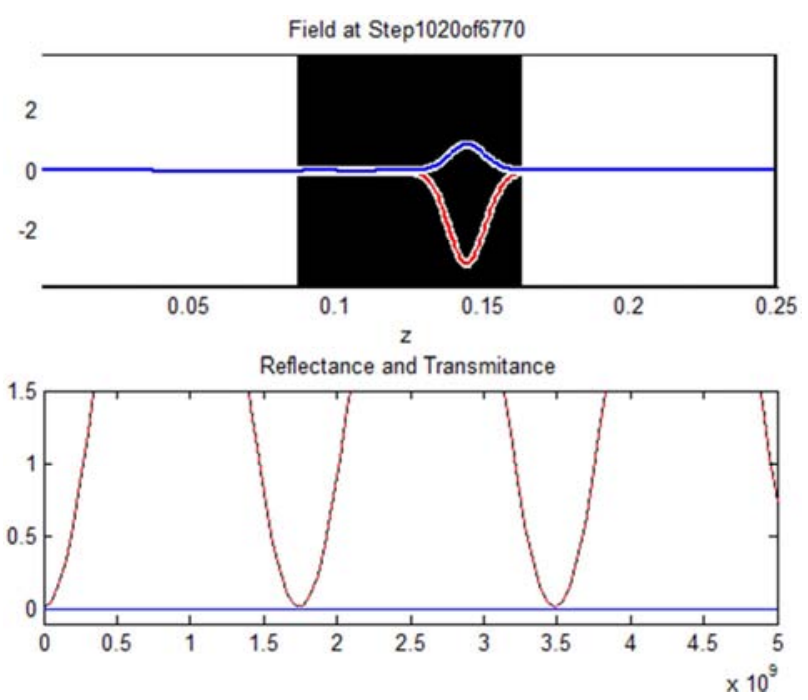

Figure 12. 1D FDTD simulations with adding a device between the free space region for measurement of transmittance and reflectance.

Figure 13 shows the 2D FDTD simulations with adding a device between the free space region for measurement of transmittance and reflectance for semiconductor material from optical purses source of laser. The time steps for simulation are 1000 based on the specific parameters from the simulation platform. The researchers could easily recognize the idea of optical properties like transmittance and reflectance and photon emission from the semiconductor devices.

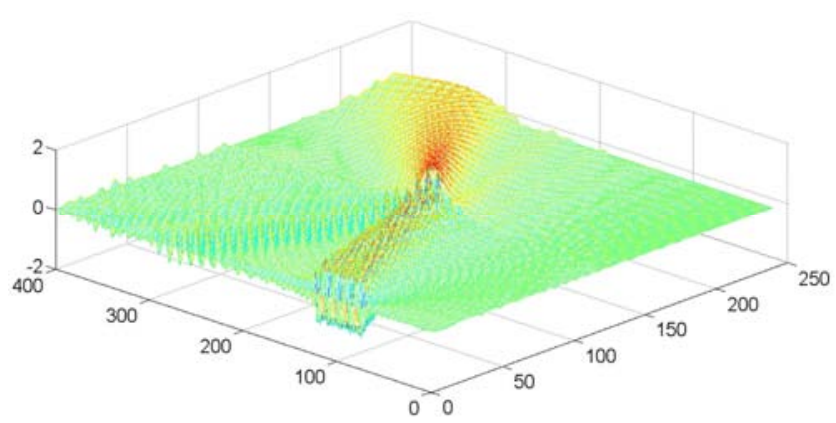

Figure 13. 2D FDTD simulations with adding a device between the free space region for measurement of transmittance and reflectance. 


\section{Statistic Table}

The Table 5 gives the statistic table for outcomes of research works with FDTD theory. Based on the statistic table, the research outcomes with FDTD theory have been successfully accomplished in the electromagnetic applied subjects like communication engineering and semiconductor engineering at YTU.

Table 5. Statistic Table for Outcomes of Research with FDTD Theory.

\begin{tabular}{llll}
\hline \multirow{2}{*}{ No } & Outcomes for Applying FDTD Theory & Year & \\
\cline { 2 - 3 } & Work Done & 2009 \\
\hline 1 & Research Paper for Electromagnetic Simulation & 2010 & Accomplishment \\
2 & Master Thesis in Application of RADAR Signal Processing & 2013 & $100 \%$ \\
3 & Research works at IIT (Delhi) (Time Reversal Focusing) & 2013 & $100 \%$ \\
4 & Research Journal at BUJICT (Time Reversal Mirror) & 2015 & $100 \%$ \\
5 & Research Report published in Germany (Time Reversal Focusing) & $100 \%$ \\
6 & Research Paper for measurement on Semiconductor Materials & $100 \%$ \\
7 & Research Papers for Optoelectronics Materials Measurement with FDTD Techniques & 2018 \\
\hline
\end{tabular}

\section{Conclusions}

The analysis on the effects of FDTD techniques on the Electromagnetic applied subjects for research and education purpose have been completed with the help of MATLAB. The education is research because original ideas and theories could help to modify or develop the novel technologies and vice versus. The research is also education based on the effective fundamental concept of technologies. The modern teaching methodologies shall be smart with the help of computer applications and simulation tools. There are four results which are based on the FDTD techniques and the simulation results are carried out from the fundamental concepts of theories. The learners could effortlessly realize the real world situations because of the technologies changes day-by-day. The FDTD techniques can change the teaching styles and research purposes for various aspects of electromagnetic applied subjects.

\section{Acknowledgements}

The author acknowledges many colleagues from the Department of Electronic Engineering of Yangon Technological University. Especially, the author appreciates Prof. Dr. Hiroshi Shirakawa (former Chief Advisor of EEHE project under JICA), Mr. Isamu Hamada (current Chief Advisor of EEHE Project under JICA) and Prof. Dr. Yoshihiro Ishitani (Professor of Graduate School of Electrical and Electronic Engineering of Chiba University) for their suggestions and advises to enhance our engineering education.

\section{References}

[1] Hla Myo Tun, "Knowledge Sharing on Research-based Education System in Japan and Myanmar", Technical Seminar on 21.12.2016. Mandalay, Myanmar

[2] Hla Myo Tun, Thant Zin Win, Kensuke Minami, Satomi Teraya, Koushi Okita, Yusui Nakamura, "Crystal Growth and Characterization of Undoped $\mathrm{ZnO}$ on m-plane Sapphire by Mist-CVD Technique with Different Carrier Gas Flow Rates",
Proceedings of the $6^{\text {th }}$ International Conference on Science and Engineering, Myanmar, 2015.

[3] Hla Myo Tun, Ryo Shoji, Bei Ma, Ken Morita1), Kenji Shiojima, nd Yoshihiro Ishitani, "Electronic transition dynamics of deep levels in a $\mathrm{p}-\mathrm{GaN}$ film analysed by time resolved PL measurements using two excitation laser beams", Proceedings of the $7^{\text {th }}$ International Conference on Science and Engineering, Myanmar, 2016.

[4] Hla Myo Tun, Hironori Sakamoto, and Yoshihiro Ishitani, "Fourier Transform Infrared (FTIR) Measurement on GaInP/Al-stripe Structure on GaAs Substrate", Proceedings of the $8^{\text {th }}$ International Conference on Science and Engineering, Myanmar, pp 115-118, 2017.

[5] Phyo Sandar Win' Hla Myo Tun, Zaw Min Naing and Win Khaing Moe, "Finite Difference Time Domain Analysis on Absorbing Boundary Condition for Solving a Time-Dependent Schrödinger Equation", Proceedings of the ASEAN Science and Technology and Innovation Conference 2017, Myanmar, 2017.

[6] Kay Thi Kyaw Min, Hla Myo Tun, Zaw Min Naing and Win Khaing Moe, "Band Structure Engineering of Group III-V and II-VI Compound Semiconductor for Thin Film Solar Cells", Proceedings of the ASEAN Science and Technology and Innovation Conference 2017, Myanmar, 2017.

[7] Phyo Sandar Win, Hla Myo Tun, Zaw Min Naing and Win Khaing Moe, "Finite Difference Time Domain Analysis on Transmittance and Reflectance of Optical Energy on Semiconductor Materials by Laser Excitation: GaN Samplebased Approach", Proceedings of the $8^{\text {th }}$ International Conference on Science and Engineering, Myanmar, 2017.

[8] Kay Thi Kyaw Min, Hla Myo Tun, Zaw Min Naing and Win Khaing Moe, "Analysis on Electrical Properties, Optical Properties and Band Engineering for III-V Semiconductor Material by Carrier Dynamics", Proceedings of the $8^{\text {th }}$ International Conference on Science and Engineering, Myanmar, 2017.

[9] Phyo Sandar Win, Hla Myo Tun, Zaw Min Naing, Win Khaing Moe, "Measurement on Magnetic Characteristics of Semiconductor Material (GaN) by FDTD Technique", Proceedings of the $40^{\text {th }}$ Research World International Conference, Singapore, pp 22-25, 2018.

[10] Kathy Kyaw Min, Hla Myo Tun, Zaw Min Naing, Win Khaing Moe, "Luminescence Lifetime Measurement on GaAs Material for Optoelectronic Devices", Proceedings of the $40^{\text {th }}$ Research World International Conference, Singapore, pp 26$29,2018$. 
[11] Frederick Ira Moxley III, Fei Zhu, Weizhong Dai, “A Generalized FDTD Method with Absorbing Boundary Condition for Solving a Time-Dependent Linear Schrödinger Equation", American Journal of Computational Mathematics, Vol. 2, pp. 163-172, 2012.
[12] Raymond C. Rumpf., Electromagnetic Analysis Using FiniteDifference Time-Domain. Lecture Notes in FDTD. USA, 2012. 